Article

\title{
Cloning, Expression, Purification and Crystallization of the PR Domain of Human Retinoblastoma Protein-Binding Zinc Finger Protein 1 (RIZ1)
}

Wanpeng Sun ${ }^{1}$, C. Ronald Geyer ${ }^{2}$ and Jian Yang ${ }^{1, *}$

1 College of Pharmacy and Nutrition, University of Saskatchewan, 110 Science Place, Saskatoon, Saskatchewan, S7N 5C9, Canada

E-mail: w.sun@usask.ca.E-mail: jian.yang@usask.ca

2 Department of Biochemistry, College of Medicine, University of Saskatchewan, 107 Wiggins Road, Saskatoon, Saskatchewan, S7N 5E5, Canada

E-mail: ron.geyer@usask.ca

* Author to whom correspondence should be addressed; E-mail: jian.yang@usask.ca

Received: 2 April 2008; in revised form: 28 May 2008 / Accepted: 2 June 2008 / Published: 2 June 2008

\begin{abstract}
Through alternative promoter usage, human retinoblastoma protein-interacting zinc finger gene RIZ encodes two different protein products, RIZ1 and RIZ2, which have been identified to be a tumor suppressor and a proto-oncoprotein, respectively. Structurally, the two protein products share the same amino acid sequences except that RIZ2 lacks an N-terminal PR domain with methyltransferase activity. Previous studies have shown that over-expression of RIZ2 is usually associated with depressed RIZ1 expression in different human cancers. It is generally believed that RIZ1 and RIZ2 regulate normal cell division and function using a "Yin-Yang" fashion and the PR domain is responsible for the tumor suppressing activity of RIZ1. In order to better understand the biological functions of the PR domain by determining its three-dimensional crystal structure, we expressed, purified and crystallized a construct of the PR domain (amino acid residues 13-190) in this study. The maximum size of the needle-shaped crystals was approximately $0.20 \times 0.01 \times 0.01 \mathrm{~mm}$.
\end{abstract}

Keywords: tumor suppressor, Yin-Yang regulation, zinc finger, affinity chromatography, protein crystallization 


\section{Introduction}

Human retinoblastoma protein-interacting zinc finger gene, $R I Z$, was first identified from a functional screening for retinoblastoma tumor suppressor binding genes [1,2]. It is located on the distal short arm of chromosome 1 (1q36), a region which harbors several other tumor suppressors and is frequently deleted in human cancers [3-9]. Using two different promoters, the RIZ gene encodes two different protein products, RIZ1 and RIZ2, which regulate normal cell division and function in a YinYang fashion [10-14]. RIZ2, a proto-oncoprotein, promotes cell division; whereas RIZ1, a tumor suppressor, arrests cells in the G2/M phase of the cell cycle and induces apoptosis [12-14]. Silencing of RIZ1 expression is associated with increased RIZ2 expression. This inverse correlation in RIZ expression has been observed in human hepatoma, leukemia, malignant lymphoma, breast cancer and colorectal cancer [15-19]. Delivery of RIZ1 via viral vector suppresses the growth of hepatoma and other cancer cells $[12,17]$.

RIZ1 and RIZ2 have identical amino acid sequences except that RIZ2 lacks the N-terminal PR domain region (200 amino acids, a subclass of zinc finger proteins present in PRDI-BF1/Blimp-1 and RIZ1) $[10,12,13]$. Therefore, the PR domain is likely responsible for the tumor suppressing activity of RIZ1. In vitro studies showed that the PR domain interacts with a PR binding motif (PRB) located in the C-terminal region of both RIZ1 and RIZ2 [11, 20, 21]. This interaction might play an important role in the "Yin-Yang" regulation between RIZ1 and RIZ2. Structurally related to the SET domain of the chromatin-associated proteins involved in gene expression, the PR domain is a C2-H2 type of zinc finger protein possessing histone H3K9 methyltransferase activity [14, 22]. Currently, more than 20 PR domains and 30 SET domains are identified in human [22, 23]. Amino acid sequence identity is about $45 \%$ among the PR domains, 50\% among the SET domains, and $20 \%$ between the PR and SET domains [23]. In 2005, Derunes et al. first reported the crystallization of a construct (amino acid residues 1-161) of the PR domain [22]. However, the crystallization conditions were not released and the crystal structure of the construct has not yet been reported. This research group however reported NMR structures of the same construct (re-classified as a SET domain) earlier this year [24]. Despite the availability of the NMR structures, our current crystallographic investigation on the PR domain was continued because our PR domain construct (amino acid residues 13-190) is much longer in the Cterminus and valuable information may be deduced for residues 161 to 190 from the crystal structure. In addition, comparison between the crystal structure and the NMR structures of the PR domain might reveal some key features that are crucial for its in vivo biological functions.

\section{Results and Discussion}

\subsection{Cloning and expression of DNA fragment encoding the PR domain}

As described below in the Experimental Section, a DNA fragment encoding the PR domain of RIZ1 (amino acid residues 13-190) was cloned by the polymerase chain reaction (PCR) using a plasmid DNA containing the full-length $R I Z$ gene as the template in order to characterize the PR domain by the X-ray protein crystallography. The PCR product was confirmed to have $534 \mathrm{bp}$ (Figure 1) and share $100 \%$ sequence identity with gene fragment encoding the designed PR domain construct by DNA sequencing at the Plant Biotechnology Institute, National Research Council (Saskatoon, Saskatchewan, 
Canada). Ligation of the PCR product to the expression vector pET-30a(+) at the NdeI and XhoI sites produced plasmid pET30/PR. Transformation of the plasmid pET30/PR into Escherichia coli (E. coli) BL21(DE3) cells expressed C-terminal His ${ }_{6}$-tagged recombinant PR domain. Over-expression of the PR domain was induced by isopropyl $\beta$-D-1-thiogalactopyranoside (IPTG, final concentration of 0.5 $\mathrm{mM})$.

Figure 1. Cloning of the gene fragment encoding the PR domain of RIZ1. Lanes (a) and (b) were the nucleotide markers and the PCR product, respectively.

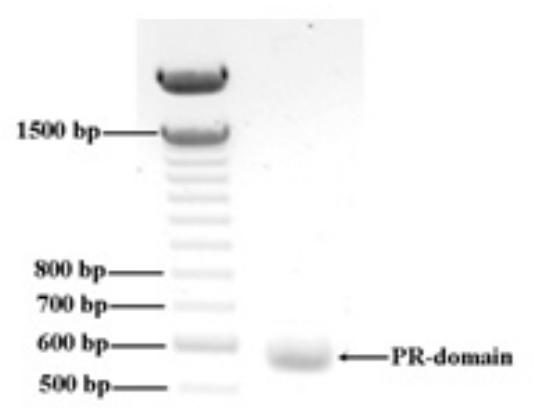

\section{(a) (b)}

Figure 2. Purification of the PR domain of RIZ1. (A). Histogram showing the elution of the PR domain on an ÄKTA ${ }^{\circledR}$ Purifier $^{\mathrm{TM}}$ FPLC system. (B). SDS-PAGE (16\%) of the purified His ${ }_{6}$-tagged PR domain. Lane $M$ was the protein standard; whereas lanes 1 to 8 were the different collected fractions of the PR domain.

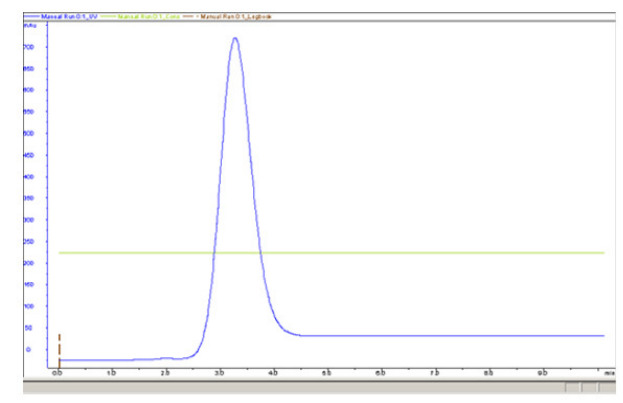

A

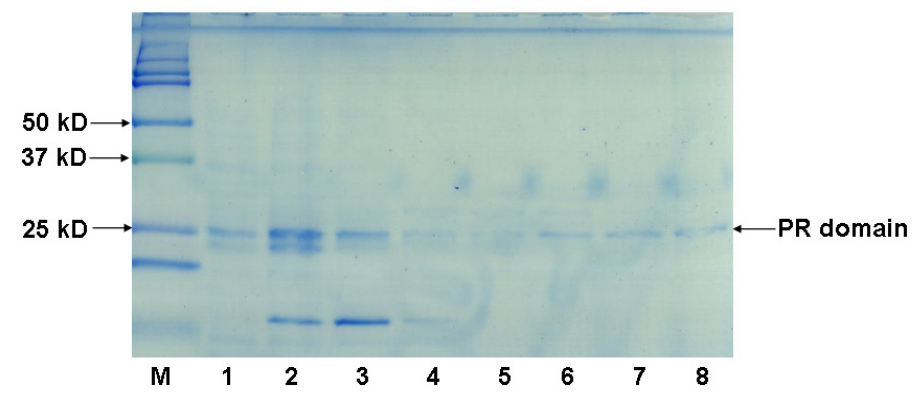

B

\subsection{Purification and activity assay of $P R$ domain}

In spite of the relatively low yield (1-2 mg purified protein per liter of cell culture), the recombinant PR domain was purified to homogeneous by affinity chromatography using a pre-packed 5-mL

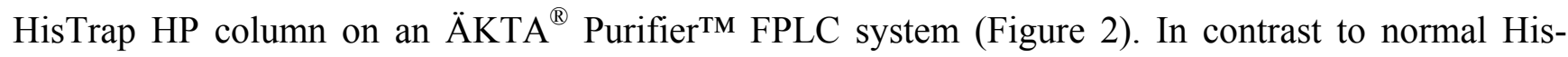
tagged protein purifications, purification of the $\mathrm{PR}$ domain was undertaken at $\mathrm{pH} 9.3$ instead of $\mathrm{pH} 7.5$ to 8.0, because the PR domain did not bind to the Ni-based HisTrap column at $\mathrm{pH} 7.5$ to 8.0, which was likely due to the high isoelectric point of the PR domain (calculated theoretical pI is 9.2). The purity of the PR domain in the collected fractions was examined on a 16\% SDS-PAGE gel (Figure 2). 
The fractions (lanes 5-8) containing pure PR domain were combined, concentrated to $1 \mathrm{mg} / \mathrm{mL}$, and stored at $-80^{\circ} \mathrm{C}$. The apparent molecular weight for the PR domain was $24 \mathrm{kDa}$ as determined from the SDS-PAGE gel, consistent with the calculated molecular weight. In order to determine whether the PR domain was active, we measured the methyltransferase activity of the PR domain using a P81 phosphocellulose filter paper based radioactive assay. As shown in Figure 3, the PR domain exhibited a concentration-dependent methyltransferase activity although the correlation between PR domain concentration and the methyltransferase was not quite linear. This indicated that the PR domain was in its active form suitable for X-ray protein crystallographic studies.

Figure 3. Radioactive assay on the methyltransferase activity of the PR domain.

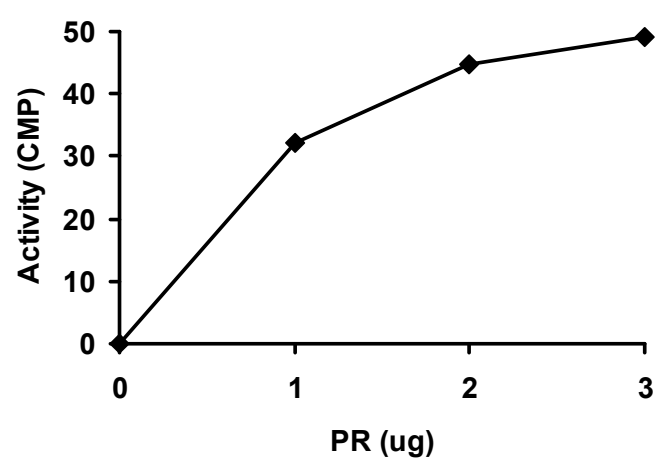

Figure 4. Crystals of the PR domain of human tumor suppressor RIZ1. (A). A cluster of the needle-shaped crystals. (B). A cluster from which a crystal (later identified to be a twin crystal) with the size of approximately $0.20 \times 0.01 \times 0.01 \mathrm{~mm}$ was obtained.

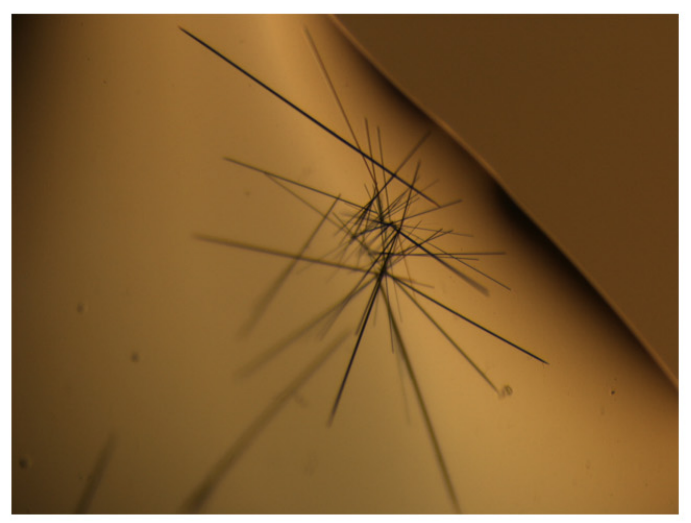

A

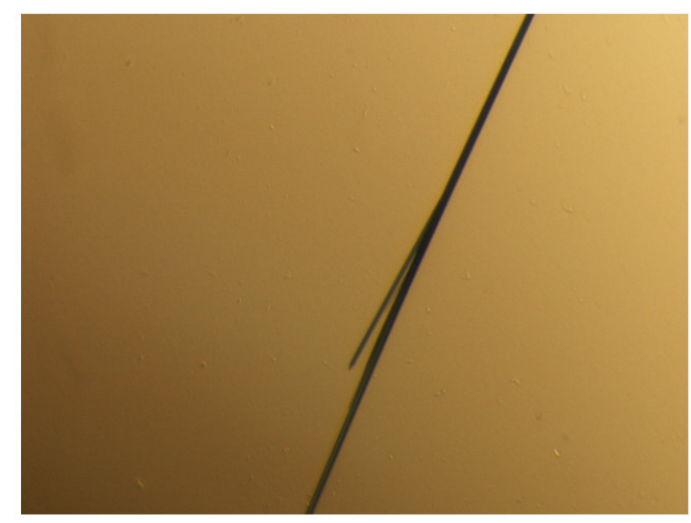

B

\subsection{Crystallization of $P R$ domain}

The initial crystallization conditions for the PR domain of RIZ1 were obtained by the hanging-drop vapor diffusion method using the commercially available Classics, Classics Lite, PEGs, PEGs II and ComPAS crystallization screening suites from Qiagen-Nextal (Mississauga, Ontario, Canada). Needleshaped crystals appeared within 5 days from the crystallization condition with the reservoir solution containing 0.1M HEPES, pH7.5, and $4 \mathrm{M} \mathrm{NaCl}$ (Figure 4). The maximum size of the needle-shaped 
crystals was $0.20 \times 0.01 \times 0.01 \mathrm{~mm}$. The crystals were capable of being stained into dark blue color using the IZIT Crystal Dye ${ }^{\mathrm{TM}}$ from the Hampton Research (California, USA), indicating that they were indeed the crystals of the PR domain. Preliminary X-ray diffraction studies at the Canadian Light Source (Saskatoon, Saskatchewan, Canada) showed that the largest crystal was a twin crystal (data not shown). Further optimization of the crystallization conditions to grow larger and thicker crystals suitable for diffraction data collection is still in progress.

\section{Experimental Section}

\subsection{Cloning and expression of the gene fragment encoding the PR domain}

Plasmid containing the full-length $R I Z$ gene was kindly provided by Dr. Shi Huang of the Burnham Institute of Medical Research. Using the plasmid DNA as the template and a pair of DNA primers (forward: 5'-CATATGCGCAGACGGACAGCGGATGC-3' with an NdeI restriction site; backward: 5'-CTCGAGGTAGCTGAAGTCCTTCAGCTC-3' with an XhoI restriction site) with their sequences corresponding to the 5' and 3' ends of the gene fragment encoding the PR domain of RIZ1 (residues 13-190), respectively, we amplified a DNA fragment of the expected size by PCR reaction on an Eppendorf $^{\mathbb{R}}$ Mastercycler ${ }^{\mathrm{TM}}$ personal thermocycler (Eppendorf Canada, Ontario, Canada). The PCR product was cleaned using a QIAquick PCR purification kit (Qiagen Canada, Ontario, Canada) and then reacted with dATP to add adenines at both ends using the Taq DNA polymerase (Invitrogen Canada, Ontario, Canada). The resultant was subject to TA cloning using a TA cloning kit (Invitrogen Canada). The new PCR product was directly ligated to the TA vector pCR2.1 and transformed into $E$. coli TOP10 cells. Plasmid DNA extracted from positive transformants was digested with restriction endonucleases NdeI and XhoI. The digested DNA fragment was first confirmed to be the gene fragment encoding the PR domain by DNA sequencing and then sub-cloned into the expression vector pET30a $(+)$ at the NdeI and XhoI sites. The resulted plasmid pET30/PR was transformed into E. coli DH5 $\alpha$ cells. Plasmid DNA was extracted from positive clones on Luria-Bertani (LB)-agar plates containing kanamycin $(30 \mathrm{mg} / \mathrm{ml})$ and transformed into E. coli BL21(DE3) cells for over-expression of the PR domain. One liter of LB plus kanamycin medium was inoculated with $1.0 \mathrm{~mL}$ of overnight culture from a single colony of transformed E. coli BL21(DE3) cells and incubated at $37{ }^{\circ} \mathrm{C}$ with shaking at $250 \mathrm{rpm}$ until $\mathrm{OD}_{600}$ of the culture reached 0.6. Protein expression was induced by adding IPTG (final concentration of $0.5 \mathrm{mM}$ ) to the cell culture. Cell growth was allowed to proceed for an additional 4 hours. The cells were harvested by centrifugation at 5,000 g for 20 minutes and the pellets were stored at $-80^{\circ} \mathrm{C}$.

\subsection{Purification of the $P R$ domain}

A frozen pellet from $1 \mathrm{~L}$ cell culture was suspended in $40 \mathrm{~mL}$ of the lysis buffer $(20 \mathrm{mM}$ Tris- $\mathrm{HCl}$, $\mathrm{pH}$ 9.3, 0.3 M NaCl, $10 \mathrm{mM}$ imidazole, $0.5 \mathrm{mM}$ phenylmethylsulphonyl fluoride (PMSF), $5 \mathrm{mM} \beta$ mercaptoethanol ( $\beta$-ME), $1 \mu \mathrm{M}$ pepstatin $\mathrm{A}$, and $1 \mathrm{~g} / \mathrm{L}$ lysozyme) and incubated with gentle rotation for $30 \mathrm{~min}$. The cells were further disrupted by sonication using a Sonifier ${ }^{\mathrm{TM}} 150$ sonicator from Branson Ultrasonics (Danbury, Connecticut, USA). The cell lysate was centrifuged at 20,000 g for 30 
min. The supernatant was loaded onto a pre-packed 5-mL HisTrap HP column from GE Healthcare Canada (Baie d'Urfé, Québec, Canada). The column was washed thoroughly with about $100 \mathrm{~mL}$ of the wash buffer (20 mM Tris-HCl, $\mathrm{pH} 9.3,0.3 \mathrm{M} \mathrm{NaCl}, 50 \mathrm{mM}$ imidazole, $0.5 \mathrm{mM}$ PMSF, $5 \mathrm{mM} \beta-\mathrm{ME}$, and $1 \mu \mathrm{M}$ pepstatin A) at a flow rate of $2 \mathrm{~mL} / \mathrm{min}$ until the elute $\mathrm{UV}$ absorbance was approximately zero. The PR domain was then eluted with $20 \mathrm{~mL}$ of the elution buffer $(20 \mathrm{mM}$ Tris- $\mathrm{HCl}, \mathrm{pH} 9.3,0.3$ $\mathrm{M} \mathrm{NaCl}, 100 \mathrm{mM}$ imidazole, $0.5 \mathrm{mM}$ PMSF, $5 \mathrm{mM} \beta$-ME, and $1 \mu \mathrm{M}$ pepstatin A). Purity of the PR domain in the elution fractions was examined on a $16 \%$ SDS-PAGE gel. Fractions containing pure PR domain were combined, and concentrated to $1 \mathrm{mg} / \mathrm{mL}$, and stored at $-80{ }^{\circ} \mathrm{C}$.

\subsection{Activity assay}

The activity of the PR domain was assayed by the methylation reaction. Briefly, the PR domain was added to a $20 \mu \mathrm{L}$ reaction solution containing $16 \mu \mathrm{M}$ radio-labeled SAM, $50 \mathrm{mM}$ Tris-HCl, $\mathrm{pH}$ 9.0, 5 $\mathrm{mM} \mathrm{MgCl}, 4 \mathrm{mM}$ dithiothreitol (DTT), and $0.125 \mathrm{~g} / \mathrm{L}$ histone $\mathrm{H} 3$ at different concentrations. The reaction solution was incubated at $30{ }^{\circ} \mathrm{C}$ for $1 \mathrm{hr}$ before spotting onto a P81 phosphocellulose filter paper. The P81 filter paper was first washed with 10\% trichloroacetic acid (15 min) three times and 95\% ethanol (1 min) once, then dried, and finally added into a scintillation vial containing $5 \mathrm{~mL}$ scintillation cocktail. The radioactivity was measured using a scintillation counter. The result was calibrated with solvent control.

\subsection{Crystallization of the PR domain}

Crystallization of the PR domain was performed by the hanging-drop vapor-diffusion method at room temperature. Initial crystallization conditions were obtained by the sparse-matrix protocol [30]. Needle-shaped crystals were obtained within 5 days from drops containing equal-volume mixtures $(2$ $\mu \mathrm{L}: 2 \mu \mathrm{L})$ of protein solution $(1 \mathrm{mg} / \mathrm{mL}$ in $10 \mathrm{mM}$ Tris- $\mathrm{HCl}, \mathrm{pH} 7.7)$ and reservoir solution $(4 \mathrm{M} \mathrm{NaCl}$, 0.1 HEPES, $\mathrm{pH} 7.5)$ equilibrated against the reservoir solution $(0.6 \mathrm{~mL})$. The crystals were confirmed to be the PR domain by staining with the IZIT Crystal Dye ${ }^{\mathrm{TM}}$ from Hampton Research (Aliso Viejo, California, USA).

\section{Conclusion}

In the current study, the PR domain (amino acid residues 13-190) of human tumor suppressor RIZ1 was cloned and over-expressed. The recombinant PR domain was confirmed to be active by the methylation reaction and crystallized by the sparse-matrix protocol. The maximum size of the needleshaped crystals was $0.20 \times 0.01 \times 0.1 \mathrm{~mm}$. Optimization of the initial crystallization conditions to obtain large crystals suitable for X-ray diffraction is in progress.

\section{Acknowledgements}

This work was supported by a research grant from the Cancer Research Society Inc. of Canada and a Research Trust fund from the College of Pharmacy and Nutrition, University of Saskatchewan. W. 
Sun would like to acknowledge the College of Pharmacy and Nutrition and University of Saskatchewan for awarding a Ph.D. scholarship.

\section{References and Notes}

1. Buyse, I. M.; Shao, G.; Huang, S. The retinoblastoma protein binds to RIZ, a zinc-finger protein that shares an epitope with the adenovirus E1A protein. Proc. Natl. Acad. Sci. USA 1995, 92, 4467-4471.

2. Buyse, I. M.; Huang, S. In vitro analysis of the E1A-homologous sequences of RIZ. J. Virol. 1997, 71, 6200-6203.

3. Buyse, I.M.; Takahashi, E.I.; Huang, S. Physical mapping of the retinoblastoma interacting zinc finger gene RIZ to D1S228 on chromosome 1p36. Genomics 1996, 34, 119-121.

4. Muraosa, Y.; Takahashi, K.; Yoshizawa, M.; Shibahara, S. cDNA cloning of a novel protein containing two zinc-finger domains that may function as a transcription factor for the human heme-oxygenase-1 gene. Eur. J. Biochem. 1996, 235, 471-479.

5. Juneja, S.; Lukeis, R.; Tan, L.; Cooper, I.; Szelag, G.; Parkin, J.D.; Ironside, P.; Garson, O.M. Cytogenetic analysis of 147 cases of non-Hodgkin's lymphoma: non-random chromosomal abnormalities and histological correlations. Br. J. Haemotol. 1990, 76, 231-237.

6. Whang-Peng, J.; Knutsen, T.; Jaffe, E.S.; Steinberg, S.M.; Raffeld, M.; Zhao, W.P.; Duffey, P.; Condron, K.; Yano, T.; Longo D.L. Sequential analysis of 43 patients with non-Hodgkin's lymphoma: clinical correlations with cytogenetic, histologic, immunophenotyping, and molecular studies. Blood 1995, 85, 203-216.

7. Cigudosa, J.C.; Parsa, N.Z.; Louie, D.C.; Filippa, D.A.; Jhanwar, S.C.; Johansson, B.; Mitelman, F.; Chaganti, R.S. Cytogenetic analysis of 363 consecutively ascertained diffuse large B-cell lymphomas. Genes Chromosomes Cancer 1999, 25, 123-133.

8. Dave, B.J.; Hess, M.M.; Pickering, D.L.; Zaleski, D.H.; Pfeifer, A.L.; Weisenburger, D.D.; Armitage, J.O.; Sanger, W.G. Rearrangements of chromosome band 1p36 in non-Hodgkin's lymphoma. Clin. Cancer Res. 1999, 5, 1401-1409.

9. Sasaki, O.; Meguro, K.; Tohmiya, Y.; Funato, T.; Shibahara, S.; Sasaki, T. Altered expression of retinoblastoma protein-interacting zinc finger gene, RIZ, in human leukaemia. Br. J. Haematol. 2002, 119, 940-948.

10. Liu, L.; Shao, G.; Steele-Perkins, G.; Huang, S. The retinoblastoma interacting zinc finger gene RIZ produces a PR domain-lacking product through an internal promoter. J. Biol. Chem. 1997, 272, 2984-2991.

11. Huang, S.; Shao, G.; Liu, L. The PR domain of the Rb-binding zinc finger protein RIZ1 is a protein binding interface and is related to the SET domain functioning in chromatin-mediated gene expression. J. Biol. Chem. 1998, 273, 15933-15939.

12. Jiang, G.; Huang, S. Adenovirus expressing RIZ1 in tumor suppressor gene therapy of microsatellite-unstable colorectal cancers. Cancer Res. 2001, 61, 1796-1798.

13. Du, Y.; Carling, T.; Fang, W.; Piao, Z.; Sheu, J.C.; Huang, S. Hypermethylation in human cancers of the RIZ1 tumor suppressor gene, a member of a histone/protein methyltransferase superfamily. Cancer Res. 2001, 61, 8094-8099. 
14. Deng, Q.; Huang, S. PRDM5 is silenced in human cancers and has growth suppressive activities. Oncogene 2004, 17, 4903-4910.

15. Mori, N.; Morosetti, R.; Spira, S.; Lee, S.; Ben-Yehuda, D.; Schiller, G.; Landolfi, R.; Mizoguchi, H.; Koeffler, H.P. Chromosome band 1p36 contains a putative tumor suppressor gene important in the evolution of chronic myelocytic leukemia. Blood 1998, 92, 3405-3409.

16. He, L.; Yu, J.X.; Liu, L.; Buyse, I.M.; Wang, M.S.; Yang, Q.C.; Nakagawara, A.; Brodeur, G.M.; Shi, Y.E.; Huang, S. RIZ1, but not the alternative RIZ2 product of the same gene, is underexpressed in breast cancer, and forced RIZ1 expression causes G2-M cell cycle arrest and/or apoptosis. Cancer Res. 1998, 58, 4238-4244.

17. Jiang, G.; Liu, L.; Buyse, I.M.; Simon, D.; Huang, S. Decreased RIZ1 expression but not RIZ2 in hepatoma and suppression of hepatoma tumorigenicity by RIZ1. Int. J. Cancer. 1999, 83, 541546.

18. Chadwick, R.B.; Jiang, G.L.; Bennington, G.A.; Yuan, B.; Johnson, C.K.; Stevens, M.W.; Niemann, T.H.; Peltomaki, P.; Huang, S.; de la Chapelle, A. Candidate tumor suppressor RIZ is frequently involved in colorectal carcinogenesis. Proc. Natl. Acad. Sci. USA 2000, 97, 2662-2667.

19. Tam, W.; Gomez, M.F.; Chadburn, A.; Knowles, D.M.; Houldsworth, J. Lack of A563G (I188V) missense mutation in RIZ/ PRDM2 in human diffuse large B-cell lymphomas. Genes Chromosomes Cancer 2007, 46, 416-418.

20. Sasaki, O.; Meguro, K.; Tohmiya, Y.; Funato, T.; Shibahara, S.; Sasaki, T. Nucleotide alteration of retinoblastoma protein-interacting zinc finger gene, RIZ, in human leukemia. Tohoku J. Exp. Med. 2002, 196, 193-201.

21. Canote, R.; Du, Y.; Carling, T.; Tian, F.; Peng, Z.; Huang, S. The tumor suppressor gene RIZ in cancer gene therapy (review). Oncol. Rep. 2002, 9, 57-60.

22. Derunes, C.; Briknarová, K.; Geng, L.; Li, S.; Gessner, C.R.; Hewitt, K.; Wu, S.; Huang, S.; Woods, V.I. Jr.; Ely, K.R. Characterization of the PR domain of RIZ1 histone methyltransferase. Biochem. Biophys. Res. Commun. 2005, 333, 925-934.

23. Kim, K.C.; Huang, S. Histone methyltransferases in tumor suppression. Cancer Biol. Ther. 2003, 2, 491-499.

24. Briknarová, K.; Zhou, X.; Satterthwait, A.; Hoyt, D.W.; Ely, K.R.; Huang S. Structural studies of the SET domain from RIZ1 tumor suppressor. Biochem. Biophys. Res. Commun. 2008, 366, 807813.

(C) 2008 by the authors; licensee Molecular Diversity Preservation International, Basel, Switzerland. This article is an open-access article distributed under the terms and conditions of the Creative Commons Attribution license (http://creativecommons.org/licenses/by/3.0/). 